Reference: Biol. Bull. 184: 6-14. (February, 1993)

\title{
Specific Inhibitors of Protein Synthesis Do Not Block RNA Synthesis or Settlement in Larvae of a Marine Gastropod Mollusk (Haliotis rufescens)
}

\author{
GABRIEL FENTEANY ${ }^{1}$ AND DANIEL E. MORSE ${ }^{2}$ \\ Department of Biological Sciences and the Marine Biotechnology Center, Marine Science Institute, \\ University of California, Santa Barbara, California 93106
}

\begin{abstract}
Antibiotic inhibitors of protein synthesis were tested for their effectiveness in larvae of the red abalone, Haliotis rufescens (gastropod mollusk). Emetine and anisomycin proved highly effective in this system, while cycloheximide, fusidic acid, puromycin, and tetracycline were less effective. Emetine and anisomycin specifically inhibited protein synthesis but not RNA synthesis. The contribution to protein synthesis by chloramphenicolsensitive prokaryotic contaminants was found to be undetectable, except following the onset of symptoms of toxicity resulting from prolonged exposure to emetine or anisomycin. The induction of larval settlement and plantigrade attachment by $\gamma$-aminobutyric acid (GABA), a functional analog of the natural inducer of settlement, occurred even under conditions in which most protein synthesis was inhibited, as expected for a chemosensory system response, whereas subsequent developmental metamorphosis was completely blocked. Because emetine and anisomycin block protein synthesis-including the synthesis of new transcription factors-but do not block early transcription, treatment of marine invertebrate embryos and larvae with these inhibitors can be used to obtain a selective enrichment in the mRNA population of "early gene" transcripts induced directly by GABA and other morphogenetic signals, without dilution by new mRNAs, the appearance of which is dependent on the synthesis of new protein transcription factors.
\end{abstract}

Received 5 August 1992; accepted 18 November 1992.

Abbreviations: GABA, $\gamma$-aminobutyric acid; TCA, trichloroacetic acid; SSC, standard sodium chloride-sodium citrate buffer.

Present address: ' Program in Cell and Developmental Biology, Harvard Medical School, Boston, Massachusetts 02115.

${ }^{2}$ Author to whom correspondence should be addressed.

\section{Introduction}

Developmentally competent larvae $(0.2 \mathrm{~mm}$ in diameter) of the marine gastropod mollusk Haliotis rufescens (red abalone) are induced to settle from the plankton and begin metamorphosis by oligopeptides and proteins associated with the surfaces of crustose red algae (Morse et al., 1979a, b, 1984; Morse and Morse, 1984), and by functional analogs of these natural inducers, such as $\gamma$-aminobutyric acid (GABA), muscimol, and baclofen (Morse et al., 1979a,b, 1980a, Morse, 1992). These compounds apparently bind to chemosensory receptors, with subsequent transduction of the signal mediated by the second messengers cyclic AMP and $\mathrm{Ca}^{++}$(TrapidoRosenthal and Morse, 1986a; Morse, 1992). This transduction pathway culminates in an excitatory depolarization that is apparently triggered by the regulated opening of chloride ion channels (Morse et al., 1980; Baloun and Morse, 1984; Morse, 1990, 1992). The morphogenetic response can be facilitated or amplified by the presence of lysine or lysine analogs (Trapido-Rosenthal and Morse, 1985,1986 b), acting through a separate lysine receptor that, in turn, stimulates a $G$ protein-diacylglycerol signal transduction cascade (Baxter and Morse, 1987, 1992; Wodicka and Morse, 1991; Morse, 1990, 1992). Before we can understand the molecular mechanisms by which these convergent chemosensory pathways regulate larval settlement behavior and the subsequent induction of gene expression controlling cellular differentiation and proliferation ( $c f$. Cariolou and Morse, 1988; Groppe and Morse, 1989; Spaulding and Morse, 1991; Degnan and Morse, 1993), we must first determine the requirements for de novo protein synthesis in these processes.

Specific inhibitors of protein synthesis, such as cycloheximide and puromycin, have proved invaluable for such 
studies in many other systems. Yet these well-known inhibitors were ineffective with larvae of the red abalone (Haliotis rufescens; gastropod mollusk) developing in seawater. This finding prompted our search for inhibitors of mRNA translation that would specifically block protein synthesis in abalone larvae in seawater media, while not inhibiting RNA synthesis.

The antibiotic protein synthesis inhibitors emetine and anisomycin exhibit the necessary effectiveness and specificity. These compounds do not inhibit RNA synthesis or the induction of settlement and plantigrade attachment of the planktonic abalone larvae, as would be expected if these processes are mediated by a chemosensory system, but they completely block the subsequent metamorphosis which, as expected, is apparently dependent on de novo protein synthesis. These inhibitors should therefore help investigators identify the primary response genes (the transcription of which does not depend on de novo protein synthesis) and messenger RNAs responsible for the induction of metamorphosis.

\section{Materials and Methods}

Haliotis rufescens broodstock was collected off the coast of Santa Barbara, California, and production and cultivation of larvae conducted as previously described (Morse et al., 1977, 1978, 1979b). Spawning was induced by exposing gravid adults to $10 \mathrm{~m} M$ hydrogen peroxide. Male and female gametes were collected and washed separately, and then mixed to allow fertilization. Embryos and larvae were maintained in $5 \mu \mathrm{m}$-filtered, U.V.-sterilized flowing seawater at $15 \pm 1{ }^{\circ} \mathrm{C}$.

Antibiotic inhibitors of protein synthesis were purchased from Sigma Chemical Company (St. Louis, Missouri), dissolved to make concentrated stock solutions and used fresh on the day of preparation. Tetracycline was purchased as the hydrochloride, fusidic acid as the sodium salt, and puromycin and emetine as the dihydrochlorides. Stock solutions were prepared in $0.22 \mu \mathrm{m}$-filtered distilled water, either alone, or containing the minimum amount of ethanol required to completely solubilize the antibiotic. After addition of antibiotics to experimental samples, no more than $0.2 \%(\mathrm{v} / \mathrm{v})$ ethanol was present in any seawater sample. Control experiments showed that the presence of $0.3 \%$ ethanol had no effect on larval behavior and settlement or on the level of $\left[{ }^{3} \mathrm{H}\right]$ leucine incorporation into TCA-insoluble material in the larvae; higher concentrations of ethanol (above $c a .0 .75 \%$ ) and other organic solvents induced settlement of the larvae, with a rapidity corresponding to the concentration of solvent (data not shown). Similar results were reported earlier by Pennington and Hadfield (1989) for larvae of the nudibranch mollusk Phestilla sibogae.
Synthesis of protein and RNA was measured by incorporation of radioactive amino acid or nucleoside into acidprecipitable macromolecules. For each assay $c a$. 2000 larvae were placed in $10 \mathrm{ml}$ of $5 \mu \mathrm{m}$-filtered, U.V.-sterilized seawater in $40 \mathrm{ml}$ Oakridge tubes. Rifampicin, a specific inhibitor of bacterial RNA synthesis, was added to a final concentration of $2.4 \mu \mathrm{M}$ in all samples to limit bacterial growth, except where otherwise noted. After incubations in the presence or absence of inhibitors, either L-[4,5${ }^{3} \mathrm{H}$ ]leucine $(150 \mathrm{Ci} / \mathrm{mmol}$; Amersham Corporation, Arlington Heights, Illinois) or $\left[5,6-{ }^{3} \mathrm{H}\right]$ uridine $(42 \mathrm{Ci} / \mathrm{mmol}$; Amersham) was added to 0.1 or $0.2 \mu \mathrm{Ci} / \mathrm{ml}$, as noted in the figure legends. For each treatment at each time point, three larval samples were used. Larvae were kept at 15 $\pm 1^{\circ} \mathrm{C}$, except as noted. To end the labeling, nonradioactive L-leucine or uridine was added to a final concentration of $0.8 \mathrm{mM}$ or $0.4 \mathrm{~m} M$, respectively. The Oakridge tubes then were centrifuged $\left(16,000 \mathrm{rpm} ; 4^{\circ} \mathrm{C}\right)$ for $5 \mathrm{~min}$ (Sorvall RC5 or RC5C Superspeed Centrifuges, Claremont, California); Sorvall SA-600 or SS-34 fixed angle rotors were used to pellet the larvae. The tubes were placed on ice, the water was drained off, $2 \mathrm{ml}$ of cold $1 \times$ SSC was added, and the larvae were re-suspended and homogenized completely in an ice-cold Dounce homogenizer ( $7 \mathrm{ml}$ Pyrex tissue grinder). One aliquot of $0.5 \mathrm{ml}$ for each sample was removed, placed in a $1.5 \mathrm{ml}$ microfuge tube, and frozen for future quantitation of protein. For each sample, $1.5 \mathrm{ml}$ of the homogenate was then placed into another microfuge tube on ice, and $100 \%(\mathrm{w} / \mathrm{v})$ trichloroacetic acid (TCA) was added to yield a final concentration of $10 \%(\mathrm{w} / \mathrm{v})$. After acid precipitation for 30 min at $4^{\circ} \mathrm{C}$, each sample was poured through a $2.4 \mathrm{~cm}$ glass microfiber filter $(\mathrm{GF} / \mathrm{C}$; Whatman International Ltd., Maidstone, UK), washed three times with 5\% TCA, then washed twice with $100 \%$ ethanol. The filters were completely dried in an oven at $55^{\circ} \mathrm{C}$ and then placed in liquid scintillation vials; $1 \mathrm{ml}$ of scintillation cocktail (Bio-Safe II; Research Products International, Mount Prospect, IL) was added and radioactivity determined by liquid scintillation. Protein was quantitated by the method of Bradford (1976) according to the protocol of the reagent manufacturer (Bio-Rad Protein Assay; Bio-Rad Laboratories, Richmond, California); assays were conducted in triplicate and evaluated relative to a bovine serum albumin standard measured in parallel. The incorporation data presented are the means of triplicate determinations, with error bars representing one standard deviation.

Assays of settlement and metamorphosis were conducted with larvae in glass scintillation vials ( $\mathrm{ca}$. 200 larvae in $10 \mathrm{ml}$ of rifampicin-containing $5 \mu \mathrm{m}$-filtered, U.V.sterilized seawater) maintained under low illumination and observed with a dissecting microscope. Each treatment was conducted in triplicate. Larvae also were placed at a density comparable to that used in the incorporation 


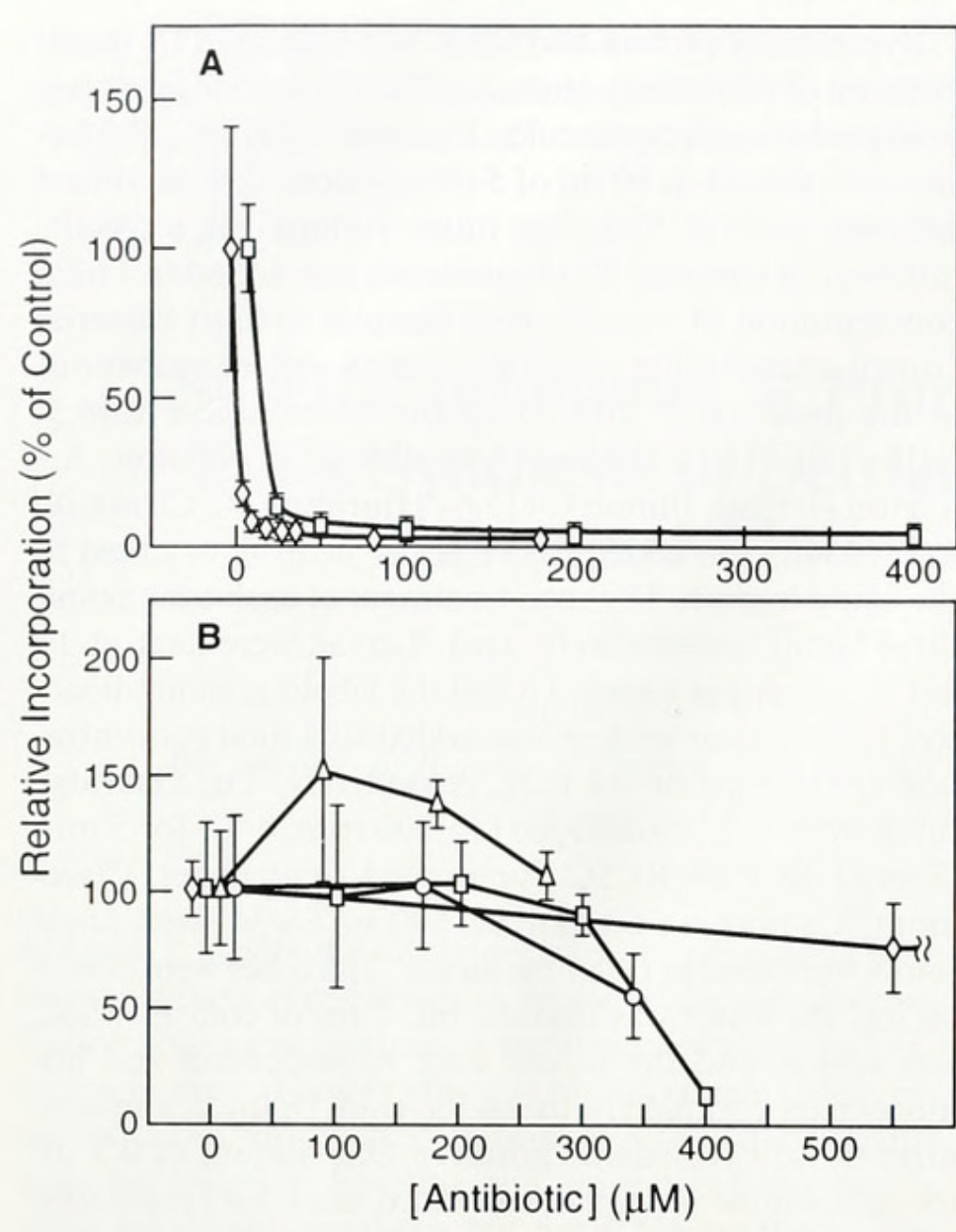

Figure 1. Incorporation of $\left[{ }^{3} \mathrm{H}\right]$ leucine as a function of the concentration of antibiotic. After incubating 8-10-day-old larvae (ca. 2,000 lar$\mathrm{vae} / 10 \mathrm{ml}$ rifampicin-containing seawater) for $2 \mathrm{~h}$ in the presence or absence of blocker at the concentrations indicated, $\left[{ }^{3} \mathrm{H}\right]$ leucine was added to $0.1 \mu \mathrm{Ci} / \mathrm{ml}$, and the pulse allowed to proceed for $2 \mathrm{~h}$. Mean control values (representing incorporation in the absence of antibiotic) are displaced on the abscissa for clarity. (A) Incorporation in the presence of emetine (diamonds) or anisomycin (rectangles). (B) Incorporation in the presence of cycloheximide (diamonds), puromycin (rectangles), tetracycline (triangles), or fusidic acid (circles). Details as described in Materials and Methods.

assays ( $c a .2000$ larvae/10 ml seawater), and observed for mortality and other responses to the protein synthesis inhibitors.

\section{Results}

\section{Inhibition of protein synthesis}

Larvae of $H$. rufescens take up exogenous amino acids from seawater, as demonstrated by these and other investigations (Jaeckle and Manahan, 1989), although these larvae are lecithotrophic. Several commonly used inhibitors of protein synthesis, including cycloheximide, fusidic acid, puromycin, and tetracycline, had little or no inhibitory effect on the overall incorporation of $\left[{ }^{3} \mathrm{H}\right]$ leucine into TCA-insoluble material at concentrations that were not toxic to the larvae (Fig. 1). In marked contrast, both emetine and anisomycin proved strongly inhibitory in a concentration-dependent manner.

Emetine $(9 \mu M)$ efficiently blocked the incorporation of $\left[{ }^{3} \mathrm{H}\right]$ leucine into Haliotis larvae under conditions in which $100 \mu M$ chloramphenicol (an inhibitor of protein synthesis only in prokaryotes) had no significant effect (Fig. 2A). Identical results were obtained for a range of chloramphenicol concentrations $(50-600 \mu M)$, both in the presence or absence of $2.4 \mu \mathrm{M}$ rifampicin (an inhibitor of bacterial RNA polymerase). Thus, in the absence of emetine, prokaryotic incorporation of $\left[{ }^{3} \mathrm{H}\right]$ leucine was not detectable. Inhibition by emetine was quite rapid; incubation for $10 \mathrm{~min}$ with $9 \mu \mathrm{M}$ emetine prior to addition of radiolabel was sufficient to block incorporation to a level comparable to that produced by an incubation for $2 \mathrm{~h}$ (data not shown). The inhibitory effect of a single

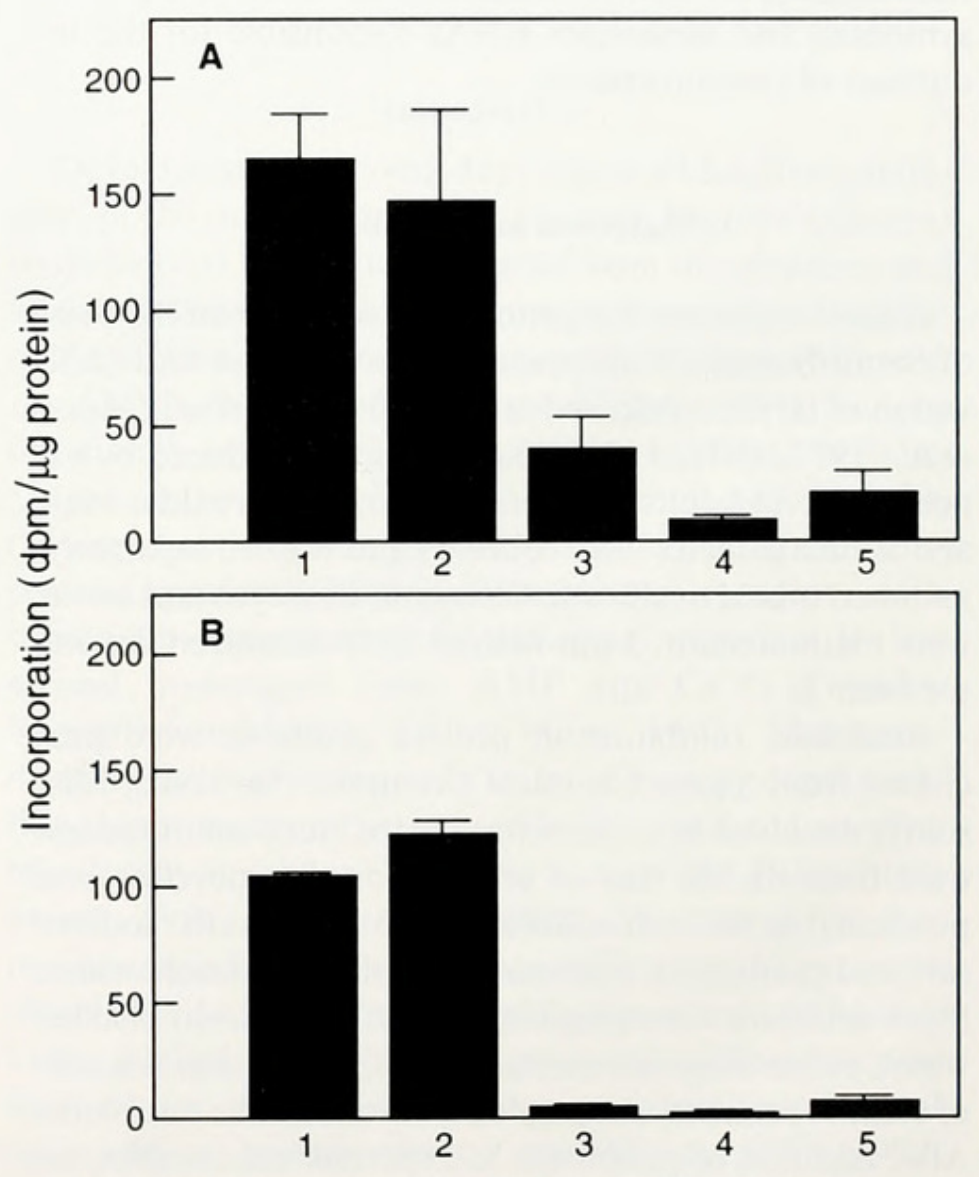

Figure 2. Incorporation of $\left[{ }^{3} \mathrm{H}\right]$ leucine in 7-day-old larvae in the presence or absence of emetine $(9 \mu M)$ or anisomycin $(200 \mu M)$ and chloramphenicol $(150 \mu M)$. 7-day-old larvae were used. Pulse-labeling at $24 \mathrm{~h}$ following the time of initial addition of emetine was for $2 \mathrm{~h}(0.1$ $\mu \mathrm{Ci} / \mathrm{ml}$ ). (A) Treatments: (1) No emetine or chloramphenicol. (2) Chloramphenicol added at 21 h. (3) Emetine added at 0 h. (4) Emetine added at $0 \mathrm{~h}$ and chloramphenicol added at $21 \mathrm{~h}$. (5) Emetine added to a concentration of $9 \mu \mathrm{M}$ at $0 \mathrm{~h}$ and the same amount added again at $12 \mathrm{~h}$. (B) Treatments: (1) No anisomycin or chloramphenicol. (2) Chloramphenicol added at $21 \mathrm{~h}$. (3) Anisomycin added at $0 \mathrm{~h}$. (4) Anisomycin added at $0 \mathrm{~h}$ and chloramphenicol added at $21 \mathrm{~h}$. (5) Anisomycin added to a concentration of $200 \mu M$ at $0 \mathrm{~h}$ and the same amount added again at $12 \mathrm{~h}$. 
addition of emetine relaxed with time (Fig. 3A), and a second addition of the same amount of emetine at $12 \mathrm{~h}$ reduced incorporation slightly further (Fig. 2A). However, following prolonged incubation in the presence of emetine, the addition of chloramphenicol $3 \mathrm{~h}$ before labeling led to significantly lower levels of incorporation, particularly at $24 \mathrm{~h}$ and $48 \mathrm{~h}$ following the addition of emetine (Figs. 2A, 3A). Therefore, some of the apparent relaxation of inhibition by emetine may be due to an increase in the proportion of protein synthesis attributable to contaminating chloramphenicol-sensitive prokaryotes. This is likely to be the result of bacterial growth on the emetinetreated larvae themselves, as these larvae become weaker, although rifampicin $(2.4 \mu M)$ was present throughout.

The inhibitory effect of a single addition of anisomycin $(200 \mu M)$ persisted longer than that caused by $9 \mu M$ emetine (Figs. 2B, 3B), and a second addition $12 \mathrm{~h}$ after the first did not reduce the incorporation of $\left[{ }^{3} \mathrm{H}\right]$ leucine further (Fig. 2B). In the presence of anisomycin, the addition of chloramphenicol $3 \mathrm{~h}$ before pulse-labeling did not lead to significantly lower levels of incorporation up to $24 \mathrm{~h}$ (Figs. 2B, 3B). Much of the inhibition of protein synthesis by a single addition of anisomycin was reversed between 24 and 48 h (Fig. 3B). This late apparent relaxation was blocked by chloramphenicol (Fig. 3B), suggesting that it was due to an increase in prokaryotic incorporation.

\section{Effects of emetine and anisomycin on RNA synthesis}

To test whether emetine affects RNA synthesis, larvae were pulsed with $\left[{ }^{3} \mathrm{H}\right]$ uridine both in the presence and absence of $10^{-6} M$ GABA (added $30 \mathrm{~min}$ following the addition of emetine). No significant inhibition of RNA synthesis was observed except at $6 \mathrm{~h}$ in the presence of both GABA and $9 \mu M$ emetine (Fig. 4A). The presence of emetine $(9 \mu M)$ may have a stimulatory effect on the incorporation of $\left[{ }^{3} \mathrm{H}\right]$ uridine in Haliotis larvae after 12.5 h. A similar experiment showed that the incorporation of $\left[{ }^{3} \mathrm{H}\right]$ uridine also was not inhibited by the addition of $200 \mu M$ anisomycin (added $60 \mathrm{~min}$ before addition of GABA; Fig. 4B).

\section{Effects of emetine and anisomycin on settlement, metamorphosis, and survival}

At concentrations sufficient to inhibit most protein synthesis, emetine and anisomycin did not block the initial induction of larval settlement and plantigrade attachment by GABA, although subsequent metamorphosis was completely blocked. Toxicity of these inhibitors was both time- and concentration-dependent. Initial settlement and plantigrade attachment of larvae induced by GABA $\left(10^{-6}\right.$ $M$ and $10^{-3} M$ ) occurred normally in the presence of 9 $\mu M$ emetine (Fig. 5A, B). Both in the presence and absence of emetine, larvae ceased their swimming behavior after

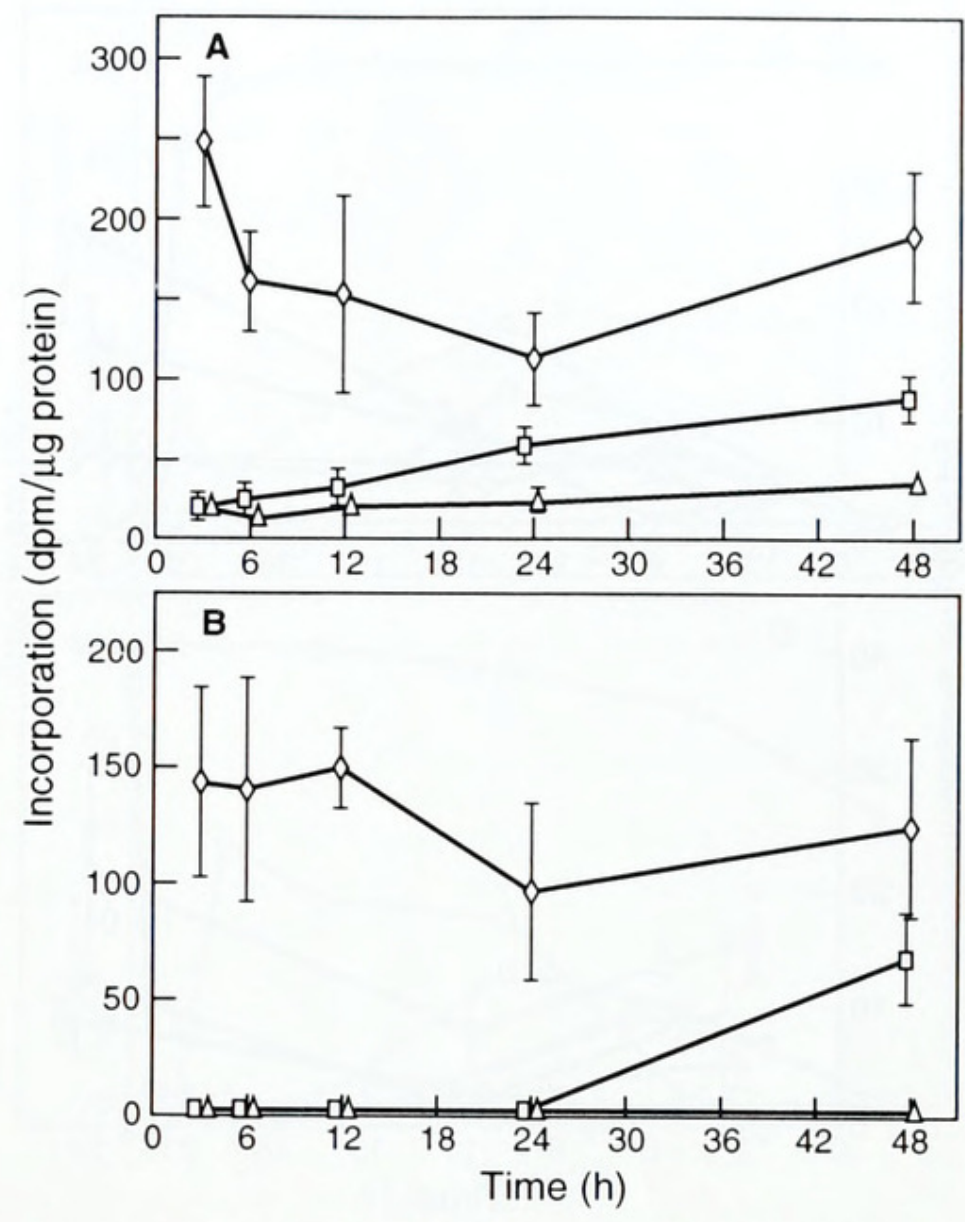

Figure 3. Incorporation of $\left[{ }^{3} \mathrm{H}\right]$ leucine in the presence or absence of emetine $(9 \mu M)$ or anisomycin $(200 \mu M)$ and chloramphenicol (150 $\mu M)$ as a function of time following addition of emetine. Larvae were pulsed at the times after addition of emetine or anisomycin indicated for $2 \mathrm{~h}(0.1 \mu \mathrm{Ci} / \mathrm{ml})$. In the chloramphenicol-treated samples, chloramphenicol was added $3 \mathrm{~h}$ prior to pulse-labeling. Mean values are displaced slightly on the abscissa for clarity. (A) 4-day-old larvae were used (6 days old by the end of the experiment in the last 3 sets of samples). No antibiotic (diamonds); emetine (rectangles); emetine plus chloramphenicol (triangles). (B) 5-day-old larvae were used (7 days old by the end of the experiment in the last 3 sets of samples). No antibiotic (diamonds); anisomycin (rectangles); anisomycin plus chloramphenicol (triangles).

addition of GABA, and plantigrade attachment followed. Attached larvae exhibited normal pedal locomotion in the presence of emetine. Abscission of the velum was also observed in the presence of emetine and occurred whether GABA $\left(10^{-6} M\right)$ was present or not, although at $9 \mu M$ emetine abscission occurred at lower levels when GABA was not present. Abscission was often premature or incomplete, particularly at higher concentrations of emetine. By $6 \mathrm{~h}$ after the addition of $10^{-6} M \mathrm{GABA}$, most of the larvae had settled both in the presence and absence of 9 $\mu M$ emetine (Fig. 5A). New shell growth was not observed in the presence of emetine when larvae were induced to settle with $10^{-6} \mathrm{M}$ GABA, although it was observed normally in settled larvae in the absence of the inhibitor by $48 \mathrm{~h}$. Attachment proceeded more rapidly at the higher 


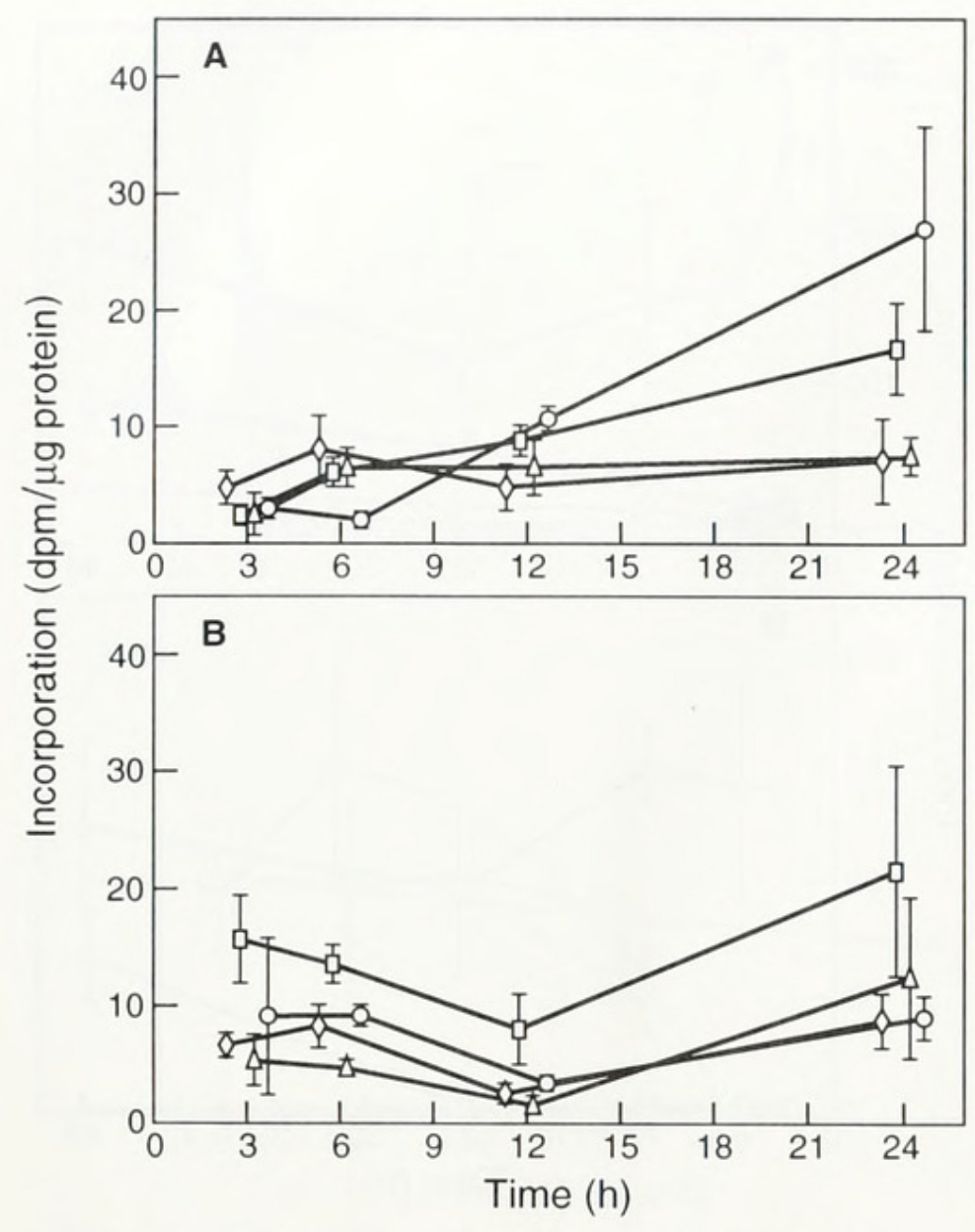

Figure 4. Incorporation of $\left[{ }^{3} \mathrm{H}\right]$ uridine in the presence or absence of emetine or anisomycin as a function of time after addition of GABA $\left(10^{-6} \mathrm{M}\right)$. The larvae were pulsed for $20 \mathrm{~min}$ with radiolabeled nucleoside $(0.2 \mu \mathrm{Ci} / \mathrm{ml})$ at the times indicated. Mean values slightly displaced on the abscissa for clarity. (A) 10-day-old larvae were used. Where indicated, emetine $(9 \mu \mathrm{M})$ was added $30 \mathrm{~min}$ prior to the addition of GABA. No emetine or GABA (diamonds); emetine with no GABA (rectangles); no emetine, plus GABA (triangles); emetine plus GABA (circles). (B) 9-dayold larvae were used. Where indicated, anisomycin $(200 \mu M)$ was added $60 \mathrm{~min}$ prior to the addition of GABA. No anisomycin or GABA (diamonds); anisomycin with no GABA (rectangles); no anisomycin, plus GABA (triangles); anisomycin plus GABA, (circles).

concentration of GABA; virtually all of the larvae were attached within $20 \mathrm{~min}$, with no inhibition by emetine (Fig. 5B). Although emetine did not inhibit the initial rate of attachment of the larvae induced by GABA, the larvae failed to maintain their plantigrade attachment (Fig. 5A, B), and progressively more were found on their sides, apparently due to the toxic effect of prolonged exposure to emetine. There also was some attachment in the presence of emetine when GABA was absent (Fig. 5A, B).

Prolonged exposure of larvae to emetine proved lethal. Even before any mortality was observed, larvae treated with $9 \mu M$ emetine appeared to spend more time on the bottom of the test vial than larvae in control vials. By $36 \mathrm{~h}$ after the addition of emetine $(9 \mu M)$ both in the presence and absence of GABA ( $c a .20$ larvae/ml), few larvae were swimming and many appeared dead, while in the control vials lacking GABA, many of the larvae remained swimming and virtually all remained alive. All the larvae were dead by $54 \mathrm{~h}$ in the presence of $9 \mu \mathrm{M}$ emetine at $c a .20$ larvae/ml, and by $72 \mathrm{~h}$ at $c a .200$ larvae/ $\mathrm{ml}$. Toxicity was progressively accelerated by higher concentrations, although the initial rate of GABA-induced attachment remained unimpaired below $80 \mu \mathrm{M}$ emetine; in the presence of $18 \mu M$ and $40 \mu M$ emetine, virtually all of the larvae were attached within $20 \mathrm{~min}$ following the addition of $10^{-3} \mathrm{M}$ GABA (data not shown). Exposure to $80 \mu M$ or $160 \mu M$ emetine produced marked symptoms of toxicity; GABA-induced settlement was reduced, premature abscission of the velum occurred in the presence and absence of GABA, and all of the larvae died within $6-12 \mathrm{~h}$ at the low density.

Anisomycin appeared to exert a stimulatory effect on the activity of the larvae, particularly on the movement of the cilia. The level of swimming activity of the larvae was markedly greater in the presence of $200 \mu M$ anisomycin than in control or emetine-treated vials, even after only $20 \mathrm{~min}$ following addition. This effect appeared to partially antagonize the initial GABA-induced attachment, with the attached larvae abnormally continuing sustained beating of their swimming cilia and displaying little pedal locomotion; plantigrade larvae often were displaced by collision with other swimming larvae, and sometimes began swimming again. The initial rates of settlement and attachment induced by $10^{-3} \mathrm{M}$ GABA were relatively unaffected by anisomycin, although longterm attachment was reduced (Fig. 5C, D). [The weak settlement-inducing activity of high concentrations of anisomycin itself ( $c f$. Fig. 5C, D) may explain the biphasic settlement observed in the presence of GABA.] Anisomycin also produced concentration-dependent and timedependent symptoms of toxicity, with complete mortality resulting from prolonged exposure ( $96 \mathrm{~h})$ of larvae, at high or low density, to $200 \mu M$ concentration.

\section{Discussion}

\section{Inhibition of protein synthesis}

Emetine and anisomycin were found to be highly effective inhibitors of protein synthesis in Haliotis larvae, whereas cycloheximide, fusidic acid, puromycin, and tetracycline proved far less effective. Possible reasons for the limited effectiveness of these widely used inhibitors may include their instability or low solubility in seawater, or their inefficient diffusion into the deeper layers of larval tissue. There is some structural evidence supporting the suggestion that membrane permeability may be an important determinant of effectiveness in the marine larval system. Emetine contains four methoxy groups, while anisomycin contains one methoxy and one acetoxy group, all carbon-linked to cyclic nuclei in both of these anti- 

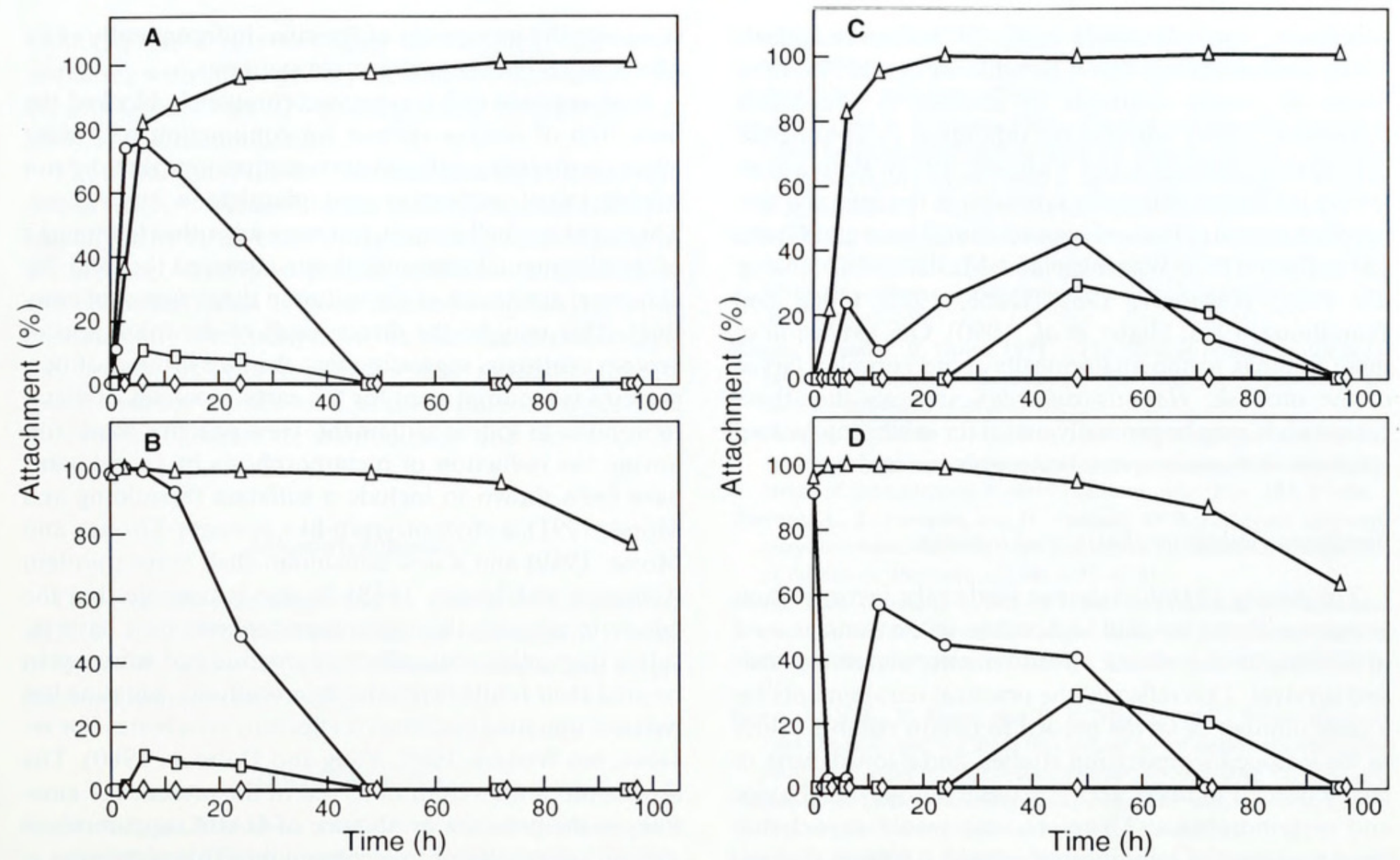

Figure 5. Attachment of larvae in the presence or absence of emetine or anisomycin as a function of time following addition of GABA. $\mathrm{Ca}$. 200 were placed in $10 \mathrm{ml}$ rifampicin-treated seawater in triplicate, as described in Materials and Methods. Following a 30-min incubation with or without emetine (A and B) or a 2-h incubation with or without anisomycin (C and D), GABA was added to the samples indicated, and the mean percentage of the larvae showing attachment was scored at the times indicated. Standard deviations for all points, assayed in triplicate, were $\leq 4 \%$. (A) 8-day-old larvae treated with or without $10^{-6} M$ GABA and $9 \mu M$ emetine. No emetine or GABA (diamonds); emetine with no GABA (rectangles); no emetine, plus GABA (triangles); emetine plus GABA (circles). (B) 8-day-old larvae treated with or without $10^{-3} \mathrm{M}$ GABA and $9 \mu M$ emetine. No emetine or GABA (diamonds); emetine with no GABA (rectangles); no emetine, plus GABA (triangles); emetine plus GABA (circles). (C) 10-day-old larvae treated with or without $10^{-6} \mathrm{M}$ GABA and $200 \mu \mathrm{M}$ anisomycin. No anisomycin or GABA (diamonds); anisomycin, with no GABA (rectangles); no anisomycin, plus GABA (triangles); anisomycin plus GABA (circles). (D) 10-day-old larvae treated with or without $10^{-3} M$ GABA and $200 \mu M$ anisomycin. No anisomycin or GABA (diamonds); anisomycin with no GABA (rectangles); no anisomycin, plus GABA (triangles); anisomycin plus GABA (circles).

biotics. These lipophilic groups may facilitate entry into cells and diffusion through tissues. This lipid solvent-like effect also might account for the weak settlement-inducing activity of these antibiotics, analogous to that reported by Pennington and Hadfield (1989) for some organic solvents. Puromycin contains only one methoxy group, and fusidic acid contains one acetoxy group.

Puromycin, which was not an effective inhibitor of protein synthesis in Haliotis larvae, has been successfully used in sea urchin embryos. Gong and Brandhorst (1988) found puromycin to effectively inhibit most protein synthesis in gastrulae of the sea urchin Lytechinus pictus in artificial seawater. On a molar basis, however, it was less effective than emetine, anisomycin, or the less readily available pactamycin. Cycloheximide dissolved in seawater-based media has limited use as a protein synthesis inhibitor in sea urchin eggs ( $\mathrm{K}$. Foltz, pers. comm.) and is a poor inhibitor of protein synthesis in sea urchin embryos (Hogan and Gross, 1971). This could be due in part to the fact that cycloheximide is rapidly inactivated in dilute alkali at room temperature, and thus may be unstable at the $\mathrm{pH}$ of seawater ( $c a$. $\mathrm{pH}$ 8). This could also help to explain its lack of effectiveness in Haliotis larvae.

Emetine and anisomycin are specific inhibitors of protein synthesis in eukaryotes; they bind to specific sites on eukaryotic ribosomes, and are ineffective in prokaryotes 
(Grollman, 1967; Barbacid et al., 1975; Carrasco et al., 1976; Jiménez et al., 1977; Sánchez et al., 1977). Inhibition of protein synthesis by emetine is irreversible (Grollman, 1968), whereas the inhibition by anisomycin is reversible (Barbacid and Vázquez, 1975). Both are effective inhibitors of protein synthesis in the eggs and embryos of several species of sea urchins (Hogan and Gross, 1971; Epel, 1972; Wagenaar and Mazia, 1978; Hille et al., 1981; Wagenaar, 1983; Dubé, 1988; Gong and Brandhorst, 1988; Sluder et al., 1990). Our extension of these findings to the anatomically more complex larvae of the mollusk, Haliotis rufescens, suggests that these compounds may be generally useful for inhibiting protein synthesis in marine invertebrate embryos and larvae.

\section{Settlement, metamorphosis, and toxicity}

The density of Haliotis larvae used in the incorporation assays was about ten-fold higher than in the samples used to investigate the effects on settlement, metamorphosis and survival. This reflected the practical requirements for a large number of larvae needed to obtain reliable values in the isotope incorporation studies, and a low density of larvae needed to make accurate observations of behavior and metamorphosis. Therefore, one would expect that the actual level of inhibition of protein synthesis that occurred in the samples in which settlement and metamorphosis were investigated would be at least equal to and probably greater than the inhibition estimated in the incorporation assays. The survival and behavior of the larvae at the higher density in the presence of the inhibitors nevertheless were found to parallel those at the lower density, although mortality generally was delayed at higher density.

The fact that the larvae initially settle and attach normally in response to GABA in the presence of emetine or anisomycin at concentrations sufficient to block nearly all protein synthesis suggests that the induction of settlement and plantigrade attachment does not require de novo protein synthesis, consistent with the notion that these behavioral responses are controlled by a chemosensory mechanism mediated by the preformed larval nervous system. It remains possible, however, that the inhibition of protein synthesis may not have been sufficient to block the synthesis of some new proteins required for this response. While the highest concentrations of emetine tested (80 $\mu M$ and $160 \mu M$ ) did interfere with initial settlement, these concentrations rapidly caused acute symptoms of toxicity, and all the larvae died within $6-12 \mathrm{~h}$ at $c a .20$ larvae $/ \mathrm{ml}$. The initial high level of induced attachment observed in response to $10^{-3} \mathrm{MGABA}$ in the presence of anisomycin was transitory, and appeared to be antagonized by the stimulatory effect of this compound on swimming activity. Emetine had no such stimulatory effect on the larvae. Anisomycin may directly or indirectly stimulate the movement of the cilia, independently of its effects as an inhibitor of protein synthesis.

Both emetine and anisomycin completely blocked the induction of metamorphosis (in conjunction with their effect on protein synthesis) at concentrations that did not inhibit initial settlement and plantigrade attachment. There was no shell growth, nor were any other landmarks of developmental metamorphosis observed (beyond the abnormal abscission of the velum in the presence of emetine). This may be the direct result of the inhibition of protein synthesis, suggesting that the biosynthesis of new proteins is required even for the early processes of metamorphosis to follow settlement. New proteins made following the induction of metamorphosis in $H$. rufescens have been shown to include a sulfatase (Spaulding and Morse, 1991), a chymotrypsin-like protease (Groppe and Morse, 1989) and a new conchiolin shell matrix protein (Cariolou and Morse, 1988). It also is possible that the failure to progress through metamorphosis may have resulted from other toxic effects of emetine and anisomycin beyond their inhibition of protein synthesis. Emetine has well-documented cardiotoxic effects in vertebrates (for reviews, see Wenzel, 1967; Yang and Dubrick, 1980). The abscission of the velum observed in the presence of emetine, in the presence or absence of GABA, apparently is a result of toxicity of this compound. This suggestion is supported by the facts that this abscission also occurs in the absence of GABA and that similar responses of the larvae to unrelated toxic compounds have been observed previously (Morse et al., 1980). Moreover, the fact that anisomycin, an equally potent but longer-lasting inhibitor of protein synthesis in the larvae, does not induce this abscission and causes less rapid mortality than does emetine at the concentrations used, supports the interpretation that this abscission is the result of toxicity rather than normal morphogenesis. However, whether the inhibition of metamorphosis is a direct result of an inhibition of protein synthesis, or the consequence of other toxic effects of the inhibitors, does not alter the principal conclusion of this study: both the initial induction of larval settlement and attachment and the overall rate of RNA synthesis are not significantly inhibited under conditions in which emetine and anisomycin block nearly all protein synthesis.

\section{Conclusions and prospects}

The embryos and larvae of marine invertebrates such as abalones and sea urchins provide highly tractable model systems for analyses of the molecular mechanisms of gene expression and gene regulation controlling behavior, cell function, cellular differentiation, and proliferation. Advantages of these systems include: egg-to-egg cultivation; the large numbers of gametes, embryos, and larvae that are readily obtainable (in some species numbering in the 
millions): the ability to trigger development and other responses with high synchrony; and the accessibility of the genes, messenger RNAs and proteins for experimental analysis and manipulation.

The conditions reported here can be used to selectively obtain mRNAs induced in marine invertebrate embryos and larvae by GABA and other morphogenetic signals in the absence of de novo protein synthesis. The isolation and characterization of such primary response (or "immediate-early") transcripts will be essential to understand the cascade of gene expression and regulatory events that transduce signals such as those induced by GABA into morphogenetic development in the larvae of $H$. rufescens.

\section{Acknowledgments}

This research was supported by grants R01-RR06640 and R01-CA53105 from the National Institutes of Health to D. E. M., and a National Defense Science and Engineering Graduate Fellowship to G. F.

\section{Literature Cited}

Baloun, A. J., and D. E. Morse. 1984. Ionic control of settlement and metamorphosis in larval Haliotis rufescens (gastropoda). Biol. Bull. 167: $124-138$.

Barbacid, M., and D. Vázquez. 1975. Ribosome changes during translation. J. Mol. Biol. 93: 449-463.

Barbacid, M., M. Fresno, and D. Vázquez. 1975. Inhibitors of polypeptide elongation on yeast polysomes. J. Antibiotics 28: 453-462.

Baxter, G., and D. E. Morse. 1987. G protein and diacylglycerol regulate metamorphosis of planktonic molluscan larvae. Proc. Natl. Acad. Sci. USA 84: 1867-1870.

Baxter, G., and D. E. Morse. 1992. Cilia from abalone larvae contain a receptor-dependent $G$ protein transduction system similar to that in mammals. Biol. Bull. 183: 147-154.

Bradford, M. A. 1976. A rapid and sensitive method for the quantitation of microgram quantities of protein utilizing the principle of proteindye binding. Anal. Biochem. 72: 248-254.

Cariolou, M. A., and D. E. Morse. 1988. Purification and characterization of conchiolin shell peptides from the marine mollusc, Haliotis rufescens, as a function of development. J. Comp. Biochem. Physiol. B 157: 717-729.

Carrasco, L., A. Jiménez, and D. Vázquez. 1976. Specific inhibitors of translocation by tubulosine in eukaryotic polysomes. Europ. J. Biochem. 64: 1-5.

Degnan, B. M., and D. E. Morse. 1993. Identification of eight homeobox-containing transcripts expressed during larval development and at metamorphosis in the gastropod mollusc Haliotis rufescens. Molec. Mar. Biol. Biotechnol. (in press)

Dubé, F. 1988. Effect of reduced protein synthesis on the cell cycle in sea urchin embryos. J. Cell. Physiol. 137: 545-552.

Epel, D. 1972. Activation of $\mathrm{Na}^{+}$-dependent amino acid transport system upon fertilization of sea urchin eggs. Exp. Cell Res. 72: 74-89.

Gong, Z., and B. P. Brandhorst. 1988. Stabilization of tubulin mRNA by inhibition of protein synthesis in sea urchin embryos. Mol. Cell. Biol. 8: 3518-3525.

Grollman, A. P. 1967. Inhibitors of protein synthesis. II. Mode of action of anisomycin. J. Biol. Chem. 242: 3226-3233.
Grollman, A. P. 1968. Inhibitors of protein synthesis. V. Effects of emetine on protein and nucleic acid biosynthesis in HeLa cells. $J$. Biol. Chem. 243: 4089-4094.

Groppe, J., and D. E. Morse. 1989. Cloning and sequence analysis of novel serine protease cDNAs from the abalone, Haliotis rufescens. Pp. 285-288, in Current Topics in Marine Biotechnology, S. Miyachi, I. Karube, and Y. Ishida, eds. Fuji Technology Press, Tokyo.

Hille, M. B., D. C. Hall, Z. Yablonka-Reuveni, M. V. Danilchik, and R. T. Moon. 1981. Translational control in sea urchin eggs and embryos: initiation is rate limiting in blastula stage embryos. Dev Biol. 86: 241-249.

Hogan, B., and P. R. Gross. 1971. The effect of protein synthesis inhibition on the entry of messenger RNA into the cytoplasm of sea urchin embryos. J. Cell Biol. 49: 692-701.

Jaeckle, W. B., and D. T. Manahan. 1989. Feeding by a "nonfeeding" larva: uptake of dissolved amino acids from seawater by lecithotrophic larvae of the gastropod Haliotis rufescens. Mar. Biol. 103: 87-94.

Jiménez, A., L. Carrasco, and D. Vázquez. 1977. Enzymic and nonenzymic translocation by yeast polysomes. Site of action of a number of inhibitors. Biochemistry 16: 4727-4730.

Morse, A. N. C., and D. E. Morse. 1984. Recruitment and metamorphosis of Haliotis larvae induced by molecules uniquely available at the surfaces of crustose red algae. J. Exp. Mar. Biol. Ecol. 75: 191215 .

Morse, A. N. C., C. Froyd, and D. E. Morse. 1984. Molecules from cyanobacteria and red algae that induce larval settlement and metamorphosis in the mollusc Haliotis rufescens. Mar. Biol. 81: 293-298.

Morse, D. E. 1985. Neurotransmitter-mimetic inducers of larval settlement and metamorphosis. Bull. Mar. Sci. 37: 697-706.

Morse, D. E. 1990. Recent progress in larval settlement and metamorphosis: closing the gaps between molecular biology and ecology. Bull. Mar. Sci. 46: 465-483.

Morse, D. E. 1992. Molecular mechanisms controlling larval metamorphosis and recruitment in abalone larvae. Pp. 107-119 in Abalone of the World, S. A. Shepherd, M. J. Tegner, and S. Guzman del Proo. eds. Blackwell, Oxford.

Morse, D. E., H. Duncan, N. Hooker, and A. Morse. 1977. Hydrogen peroxide induces spawning in mollusks, with activation of prostaglandin endoperoxide synthetase. Science 196: 298-300.

Morse, D. E., N. Hooker, and A. Morse. 1978. Chemical control of reproduction in bivalve and gastropod molluscs, III: An inexpensive technique for mariculture of many species. Proc. World Maricult. Soc. 9: 543-547.

Morse, D. E., N. Hooker, H. Duncan, and L. Jensen. 1979a. $\quad \gamma$-aminobutyric acid, a neurotransmitter, induces planktonic abalone larvae to settle and begin metamorphosis. Science 204: 407-410.

Morse, D. E., N. Hooker, L. Jensen, and H. Duncan. 1979b. Induction of larval abalone settling and metamorphosis by $\gamma$-aminobutyric acid and its congeners from crustose red algae, II: Applications to cultivation, seed-production and bioassays; principal causes of mortality and interference. Proc. World Maricult. Soc. 10: 81-91.

Morse, D. E., H. Duncan, N. Hooker, A. Baloun, and G. Young. 1980. GABA induces behavioral and developmental metamorphosis in planktonic molluscan larvae. Fed. Proc. 39: 3237-3241.

Pennington, J. T., and M. G. Hadfield. 1989. Larvae of a nudibranch mollusc (Phestilla sibogae) metamorphose when exposed to common organic solvents. Biol. Bull. 177: 350-355.

Sánchez, L., D. Vázquez, and A. Jiménez. 1977. Genetics and biochemistry of cryptopleurine resistance in the yeast Saccharomyces cerevisiae. Mol. Gen. Genetics 156: 319-326.

Sluder, G., J. M. Miller, R. Cole, and C. L. Rieder. 1990. Protein synthesis and the cell cycle: Centrosome reproduction in sea urchin eggs is not under translational control. J. Cell Biol. 110: 2025-2032. 
Spaulding, D. C., and D. E. Morse. 1991. Purification and characterization of sulfatases from Haliotis rufescens: Evidence for changes in synthesis and heterogeneity during development. J. Comp. Physiol. B. 161: 498-515.

Trapido-Rosenthal, H. G., and D. E. Morse. 1985. L- $\alpha, \omega$-Diamino acids facilitate GABA induction of larval metamorphosis in a gastropod mollusc (Haliotis rufescens). J. Comp. Physiol. B. 155: 403414

Trapido-Rosenthal, H. G., and D. E. Morse. 1986a. Availability of chemosensory receptors is down-regulated by habituation of larvae to a morphogenetic signal. Proc. Natl. Acad. Sci. USA 83: $7658-$ 7662.

Trapido-Rosenthal, H. G., and D. E. Morse. 1986b. Regulation of receptor-mediated settlement and metamorphosis in larvae of a gastropod mollusc (Haliotis rufescens). Bull. Mar. Sci. 39: 383-392.
Wagenaar, E. B. 1983. The timing of synthesis of proteins for mitosis in the cell cycle of the sea urchin embryo. Exp. Cell Res. 144: $393-$ 403 .

Wagenaar, E. B., and D. Mazia. 1978. The effect of emetine on first cleavage division in the sea urchin, Strongylocentrotus purpuratus. Pp. 539-545 in Cell Reproduction. E. R. Dirksen, D. M. Prescott, and C. F. Fox, eds. Academic Press, New York.

Wenzel, D. G. 1967. Drug-induced cardiomyopathies. J. Pharm. Sci 56: $1209-1224$.

Wodicka, L. M., and D. E. Morse. 1991. cDNA sequences reveal mRNAs for two $\mathrm{G} \alpha$ signal transducing proteins from larval cilia. Biol. Bull. 180: 318-327.

Yang, W. C. T., and M. Dubrick. 1980. Mechanism of emetine cardiotoxicity. Pharm. Ther. 10: 15-26. 


\section{$2 \mathrm{BHL}$ Biodiversity Heritage Library}

Fenteany, Gabriel and Morse, D E. 1993. "Specific Inhibitors of Protein Synthesis Do Not Block RNA Synthesis or Settlement in Larvae of a Marine Gastropod Mollusk (Haliotis rufescens)." The Biological bulletin 184, 6-14. https://doi.org/10.2307/1542375.

View This Item Online: $\underline{\text { https://www.biodiversitylibrary.org/item/17366 }}$

DOI: https://doi.org/10.2307/1542375

Permalink: https://www.biodiversitylibrary.org/partpdf/37196

\section{Holding Institution}

MBLWHOI Library

\section{Sponsored by}

MBLWHOI Library

\section{Copyright \& Reuse}

Copyright Status: In copyright. Digitized with the permission of the rights holder.

License: http://creativecommons.org/licenses/by-nc-sa/3.0/

Rights: https://biodiversitylibrary.org/permissions

This document was created from content at the Biodiversity Heritage Library, the world's largest open access digital library for biodiversity literature and archives. Visit BHL at https://www.biodiversitylibrary.org. 